\title{
Depression, Anxiety and Stress Among International Postgraduate Students in a Uk University: A Cross-Sectional Study
}

Olivia C. Ejim

University of Birmingham

Maria Livanou

Kingston University

Harun Khan

Sandwell \& West Birmingham Hospitals NHS Trust

Antje Lindenmeyer

University of Birmingham

Chinedum Uwom

Medigold Health

Semira Manaseki-Holland ( $\sim$ s.manasekiholland@bham.ac.uk)

University of Birmingham

\section{Research Article}

Keywords: depression, anxiety, stress, international postgraduates, university

Posted Date: March 19th, 2021

DOI: https://doi.org/10.21203/rs.3.rs-287018/v1

License: (c) (i) This work is licensed under a Creative Commons Attribution 4.0 International License. Read Full License 


\section{Abstract}

Background: Little is known about the prevalence of DAS among postgraduate international students in the UK. The study aimed to determine in these students the prevalence, associated individual characteristics, life and academic challenges related to DAS and suicidal thoughts, and management strategies used by the affected students.

Methods: This cross-sectional study was conducted at a large English university. Self-selected postgraduate international students, aged 20-50 years, participated through online and paper questionnaires. The World Health Organisation's Self-Reporting Questionnaire (SRQ-20) was used to indicate the presence of DAS. Additional open questions explored social and academic challenges, and coping strategies.

Results: Amongst the 289 participants, 43\% ( $n=123)$ presented with DAS and 12\% ( $n=34)$ experienced suicidal thoughts. In the multivariate analysis, significant independent predictors $(p \leq 0.05)$ were length of stay in the UK ( $>3$ years) and studying in a certain faculty. Significant challenges associated with DAS included relationship issues, inadequate finances, homesickness, difficulty carrying out domestic chores, problem finding a community with shared cultural/religious values, change of climate, and perceived insufficient support from university staff. Coping strategies included talking to academic advisors/tutors, friends/family in the UK or their home country. Of all students with DAS and suicidal thoughts, $25 \%$ and $21 \%$, respectively sought medical help, and $17 \%$ and $32 \%$ were on medication.

Conclusion: International postgraduates had higher rates of DAS and suicidal thoughts than the UK population. A low percentage sought medical help, which has implications for service planning. A model of influencing factors is presented, requiring future studies.

\section{Background}

In 2017, the top destinations amongst the Organization for Economic Co-operation and Development (OECD) member countries for international students were the United States (US) and the United Kingdom (UK). Of the 3.7 million international students population, $22 \%$ and $10 \%$ were in the US and UK respectively (1). Furthermore, the proportion of students studying at Masters and Doctorate levels made up $13 \%$ and $26 \%$ of the US(985,000), and $34 \%$ and $42 \%$ of the UK $(436,000)$ international students respectively $(1)$. Beyond academic challenges relating to their courses, a large number of students face additional social challenges, such as new learning styles and cultural adjustment, which may increase the risk of developing subsequent mental health disorders (2-4).

In the UK, there has been a five-fold increase in mental health problems in comparison with other disabling conditions among university students in the past decade, which is of national concern and challenging the healthcare system (5-7). Previous research has shown that starting university marks a transitional period in young people's lives which comes with additional mental health risks due to a number of psychosocial and emotional changes taking place (8). There is increasing evidence that those between 18 to 29 years are more likely to present with mental health symptoms (9). Moving to a new country compounds what may be an already stressful life situation. Accordingly, international postgraduate students experience several transitions and difficulties at different levels, which may explain high prevalent rates of mental health problems in this group.

The academic expectations imposed by universities can be stress-provoking. Elevated stress levels and symptoms have been reported in students with a predisposition to depression, anxiety and stress (DAS) and/or mental health disorders $(10,11)$. These can include depression and generalised anxiety disorders- with bipolar affective disorder and schizophrenia being less common $(12,13)$. Behaviours related to mental health, such as suicidal ideation, are also more common amongst postgraduates specifically (14).

The prevalence of mental health disorders amongst university student populations has been reported as up to $30.6 \%$, according to an extensive global systematic review of 24 papers by Ibrahim et al. (2013) (15). These findings are in line with studies conducted in the UK (16-18). It is arguable that international postgraduate students are at a further increased risk of developing mental health disorders in comparison with the average population due to the presence of additional social and cultural challenges (19). For example, studies in the USA demonstrate that DAS prevalence was $13 \%$ amongst non-international postgraduates (assessed using the Patient Health Questionnaire (PHQ-9)), and 44\% amongst international students (assessed using an unspecified web-based survey) $(19,20)$. Furthermore, one study in the US explored the situation of DAS with international postgraduate students (19).

A high reported burden of mental health amongst university populations, especially international students, reflects a significant public health issue that, if not addressed, can have increasing health, social and economic implications within the host universities $(6,21,22)$ and upon students' return home. This is due to the rising number of international students in most countries (1). There is a scarcity of DAS prevalence data amongst international graduates or postgraduates in the UK. Therefore, this study aimed to identify the prevalence of DAS among international postgraduate students attending a large UK university using a validated questionnaire (SRQ-20). Our secondary aim was to investigate possible predictors for developing DAS and health seeking behaviours for those at risk.

\section{Methods}

\section{Research Design/Setting}

A cross-sectional study in a large UK university, with a high proportion of international students for postgraduate study across all departments.

Page 2/21 


\section{Study Population}

According to university records, during the academic year 2014/15, 34,165 students were registered with this university of which $24 \%$ were international students. Of all students in the university, 14,060 (41\%) were enrolled as postgraduate students, $33 \%$ of which $(4,680)$ were international students.

The inclusion criteria for this study were postgraduate student status (Masters or PhD level); with an international student status and registered for academic year 2014/15 at the university. Participants who did not answer all SRQ-20 questions were excluded from the analysis.

\section{Sample Size}

Having considered previous studies of university students and international postgraduates from the US, the prevalence of DAS was estimated to be $15 \%(19,20)$. Using this data, a minimum sample size of 270 was derived after power calculations, at $5 \%$ default level of precision and $95 \% \mathrm{Cl}(23)$.

\section{Data Collection}

Data was collected from July to September 2015 using self-selected sampling.

Several methods were used to encourage students to complete the questionnaire (24). The online questionnaire was promoted using social media. Links to the online questionnaire were posted in group discussions on social media platforms for international postgraduate students, on Facebook and WhatsApp.

Paper questionnaires were placed in venues in all departments for postgraduate students on campus and when possible a member of the research team was present to direct international postgraduate students as necessary - those completing paper versions were given pre-paid postage envelopes. Additionally, international postgraduate students in two departments (in faculties of Life Sciences and Medical Sciences) of the university received paper questionnaires directly through the post.

The questionnaire collected demographic data. To ensure anonymity, potential identifiers were not asked during the study, so those with significant mental health distress could not be contacted directly. However, the questionnaire also included information on support services available on campus for students.

This study used the SRQ-20 questionnaire to detect DAS as it is a validated tool and easy-to-use (25). Question 17 asked about suicidal thoughts. Questions were prefaced by a line asking students to answer the question in a way that suited the way they felt in recent days or at the current time.

We used previous literature to identify additional questions relating to academic and social challenges that may impact the mental health status of international postgraduate students $(22,26)$. Subsequent coping strategies were also examined. Lastly, a section allowed the participants to write in free text to communicate anything not covered by the rest of the questionnaire.

The questionnaire was in simple and concise English only, since English language proficiency is a requirement prior to enrolment into UK universities. The questions were assessed for face validity by academic clinicians within the Department of Public Health and piloted with a group of international students.

\section{Data Analysis}

Data was analysed with STATA software (version 14). Individual scores of any SRQ-20 item, such as scores for suicidal thoughts, and the overall SRQ20 scores ( $\geq$ or $<5$ ), were treated as binary outcomes. A cut-off of $\geq 5$ reflected the presence of DAS. This cut-off has been validated for sensitivity and specificity when screening for DAS in previous research $(27,28)$ - including research based in the UK $(29)$. Logistic regression was used to identify possible predictors associated with DAS. Chi-square test was used to separately determine whether there was evidence of association between social/life and academic challenges and DAS. Multiple logistic regression analysis was used to control for potential moderating factors. This was represented using odds ratios at $95 \% \mathrm{Cl}$ and a statistically significant $\mathrm{p}$-value of $\leq 0.05$.

The free-text responses were analysed thematically to provide further insight on the quantitative data (30). Through guided analysis, codes were devised for the most commonly occurring themes (31).

\section{Results}

\section{Sample Description}

Of approximately 4,680 international postgraduates enrolled in the university, 327 students returned the questionnaire (7\% response rate). Thirty-eight questionnaires were excluded, as they were incomplete in the SRQ-20 item section (see Figure A in Appendix).

\section{Demographic information and the prevalence of DAS}


Of the participants 149 (51\%) were between 20-24 years old, 255 (88\%) were enrolled on taught programmes (for example masters) and 152 (52\%) had lived in the UK for $<1$ year - with $47 \%$ having worked before commencing study in the UK. A large proportion of the respondents were female (63\%), from East/Central Asia (49\%), were middle-class (74\%) and studied a subject relating to social science (53\%).

The SRQ-20 scores ranged from 0 to 20 with a mean score of 4.69 (SE \pm 0.25$)$. Overall, the prevalence of DAS was $43 \%$ (95\%Cl 37,49$)$. Females suffered from significantly higher rates of DAS (Table 1).

\section{Table 1}

Basic Demographic information of the respondents with corresponding DAS and Suicidal Thoughts status. Number and percentage used, unless stated otherwise. Logistic regression and multivariate analysis to identify possible predictors of having DAS and Suicidal Thoughts. 


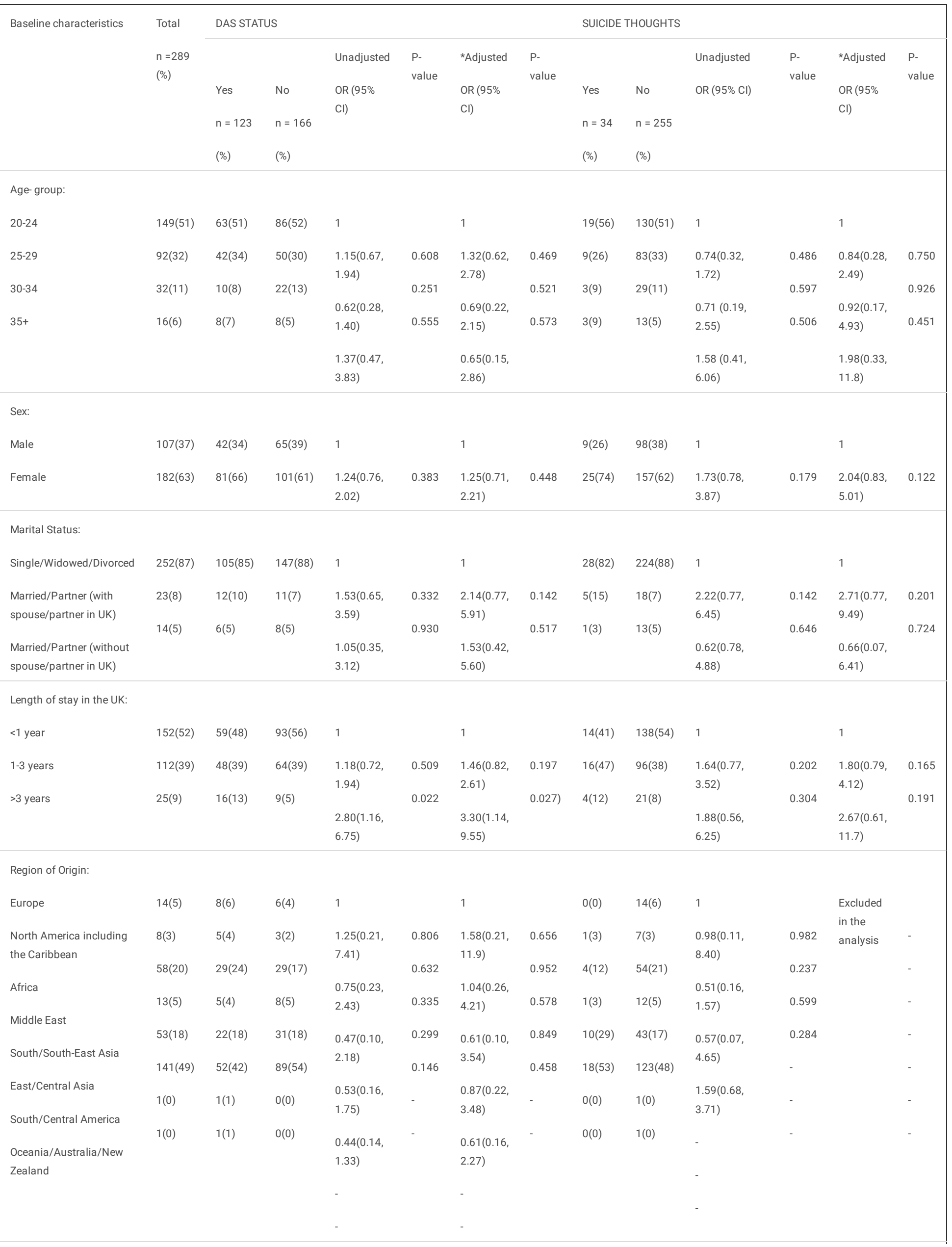




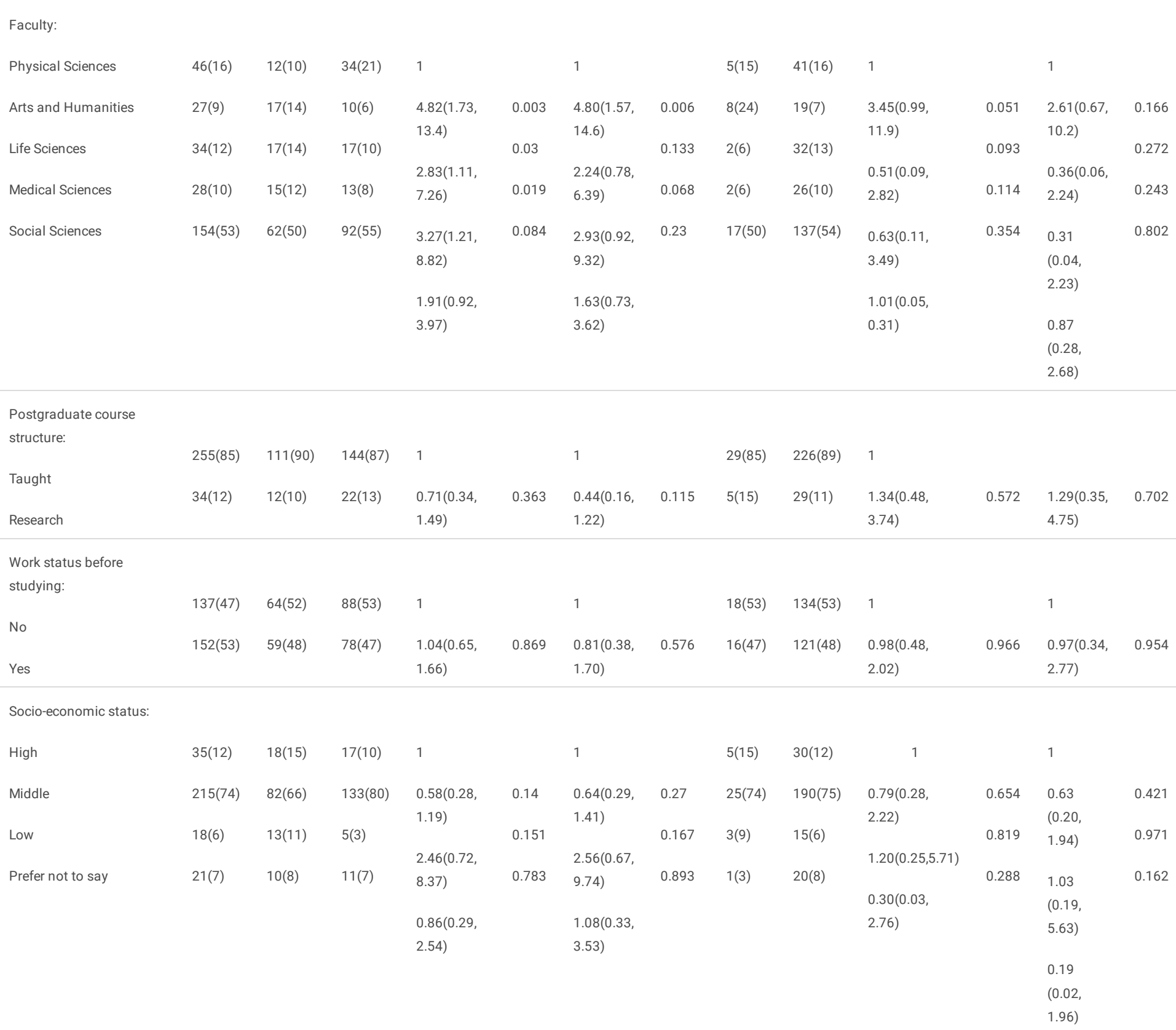

Notes: For the sake of anonymity, we have changed the actual name of the faculties but kept to the general subject area. 95\% Cl: $95 \%$ confidence interval; OR: Odds ratio; $p$-value <0.05:

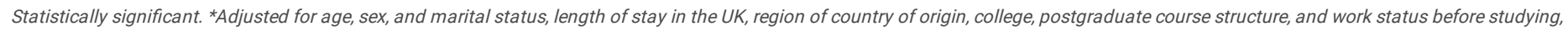
and socio-economic status in the analysis for DAS status, while for Suicide Thoughts Region of origin was excluded in the *Adjusted analysis.

\section{Suicidal Thoughts}

Overall, $34(12 \%)$ students reported experiencing suicidal thoughts; this was more common amongst females (OR=1.73). Of all participants who reported suicidal thoughts, 26 (76\%) had DAS based on the SRQ-20 score cut-off of $\geq 5$. (Figure 1 )

\section{Predictors of DAS and Suicidal Thoughts}

In the univariate analysis, the following variables were associated with having DAS: length of stay in the UK >3 years and studying in a certain faculty (Table 1), both of which remained independently associated after multivariate analysis: length of stay in UK >3 years (OR=3.30, 95\% Cl 1.14, 9.55; $\mathrm{p}=0.027)$ and studying in Arts and Humanities (OR=4.80,95\% $\mathrm{Cl} 1.57,14.6 ; \mathrm{p}=0.006)$.

Suicidal thoughts were also independently associated with staying >3 years in the UK and studying an Arts and Humanities subject. 


\section{Social Factors Associated with DAS and Suicidal Thoughts}

Table 2A shows several social factors that were associated with having DAS in this study. On univariate analysis, those who met the criteria for DAS were significantly more likely (at least by a factor of 2) to report challenges pertaining to: finances, managing day-to-day chores, personal relationships, missing family and/or a support network, finding people with similar interests and adjusting to the weather. Financial constraints, and finding people with similar interests were independent factors that remained associated with DAS on multivariate analysis.

For those with suicidal thoughts, feeling unwelcome in the UK, and issues with personal relationship were challenging and remained independent variables in the multivariate analysis.

Table 2A

Possible social challenges that could predict having DAS and Suicidal Thoughts based on a 'Yes' response except for feeling welcomed. Numbers and percentages used unless stated otherwise. Logistic regression and multivariate analysis to identify possible predictors of having DAS and Suicidal Thoughts. 


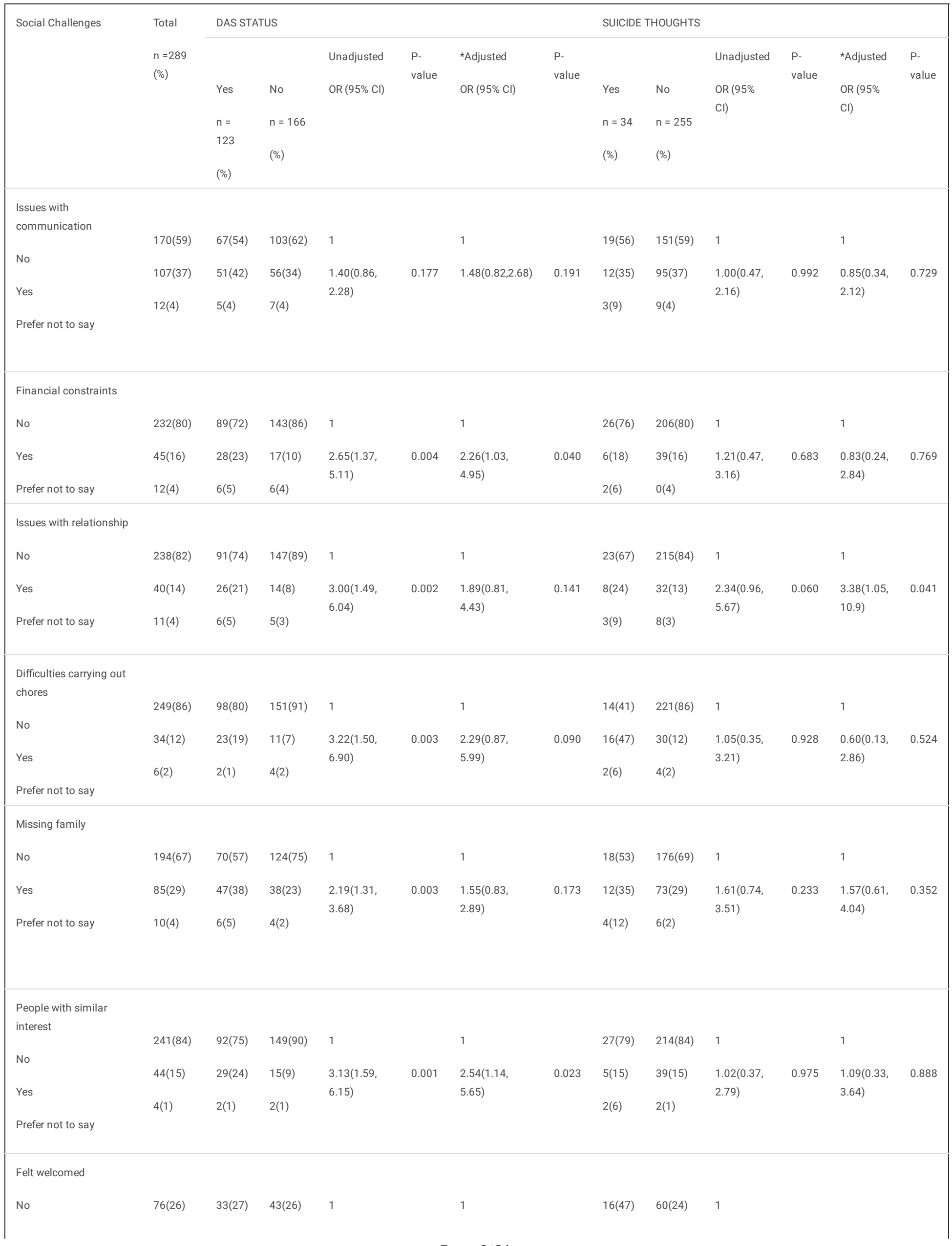




\begin{tabular}{|c|c|c|c|c|c|c|c|c|c|c|c|c|c|}
\hline $\begin{array}{l}\text { Yes } \\
\text { Prefer not to say }\end{array}$ & $\begin{array}{l}172(60) \\
41(14)\end{array}$ & $\begin{array}{l}70(57) \\
26(16)\end{array}$ & $\begin{array}{l}102(61) \\
21(13)\end{array}$ & $\begin{array}{l}0.89(0.52 \\
1.54)\end{array}$ & 0.688 & $\begin{array}{l}0.72(0.38 \\
1.38)\end{array}$ & 0.323 & $\begin{array}{l}13(38) \\
5(15)\end{array}$ & $\begin{array}{l}159(62) \\
36(14)\end{array}$ & $\begin{array}{l}0.31(0.14 \\
0.68)\end{array}$ & 0.003 & $\begin{array}{l}1.25(0.10 \\
0.62)\end{array}$ & 0.003 \\
\hline $\begin{array}{l}\text { Poor adjustment } \\
\text { weather }\end{array}$ & 156(54) & $58(47)$ & $98(59)$ & 1 & & 1 & & 19(56) & $137(54)$ & 1 & & 1 & \\
\hline $\begin{array}{l}\text { No } \\
\text { Yes }\end{array}$ & $\begin{array}{l}125(53) \\
8(3)\end{array}$ & $\begin{array}{l}63(51) \\
2(2)\end{array}$ & $\begin{array}{l}62(37) \\
6(4)\end{array}$ & $\begin{array}{l}1.72(1.06 \\
2.77)\end{array}$ & 0.027 & $\begin{array}{l}1.55(0.85 \\
2.82)\end{array}$ & 0.157 & $\begin{array}{l}12(35) \\
3(9)\end{array}$ & $\begin{array}{l}113(44) \\
5(2)\end{array}$ & $\begin{array}{l}0.77(0.36 \\
1.65)\end{array}$ & 0.494 & $\begin{array}{l}0.53(0.19 \\
1.45)\end{array}$ & 0.216 \\
\hline Prefer not to say & & & & & & & & & & & & & \\
\hline
\end{tabular}

Table 2B

Possible academic challenges that could predict having DAS and Suicidal Thoughts based on a 'No' response if it is a problem. Logistic regression and multivariate analysis to identify possible predictors of having DAS and Suicidal Thoughts. 


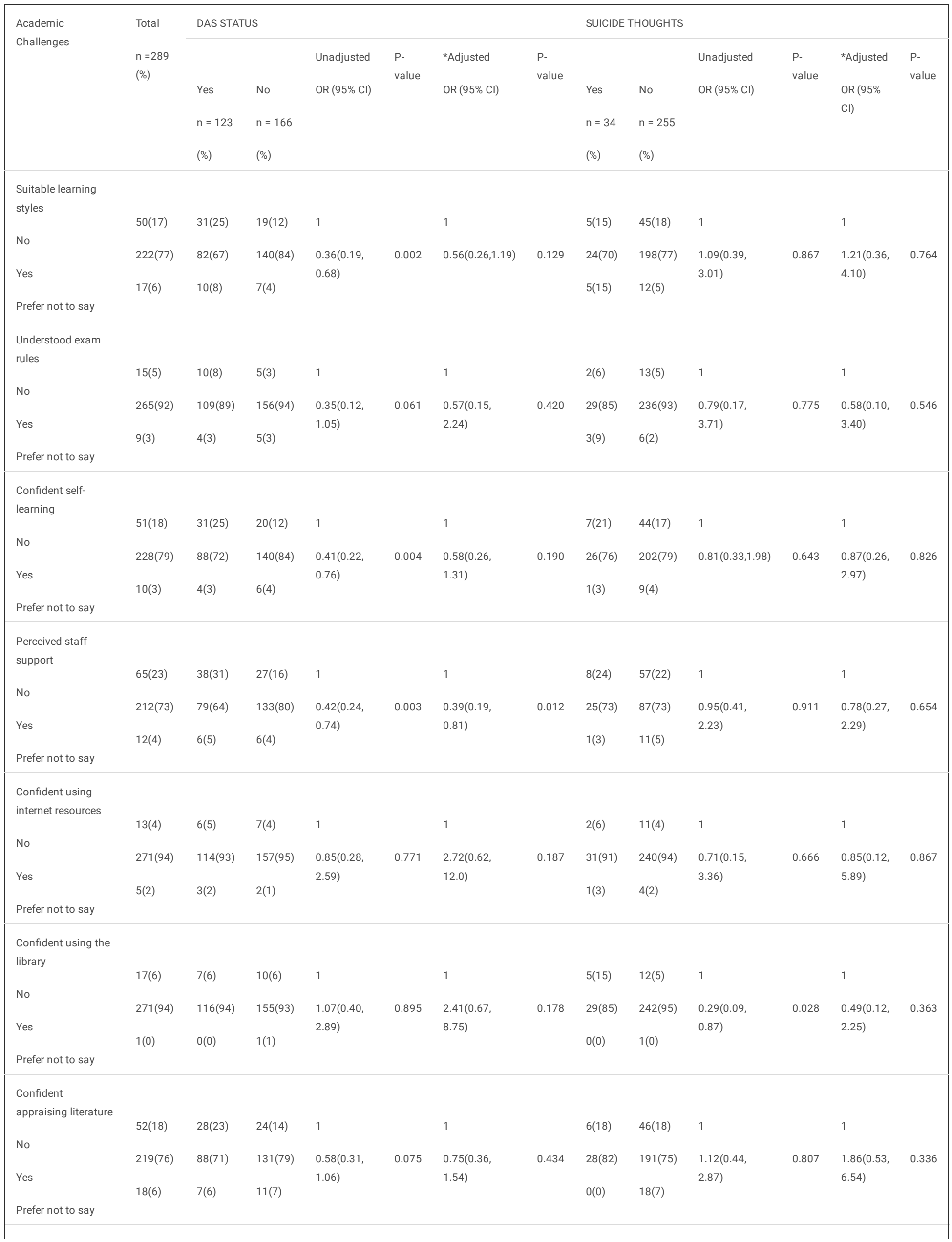




\section{Academic Factors associated with DAS and Suicidal Thoughts}

Challenging factors of an academic nature that were significantly associated with having DAS are shown in Table 2B. On univariate analysis, these academic challenges included: being faced with unfamiliar learning styles, confidence on critically appraising the academic literature (an integral part of postgraduate work), and low confidence levels relating to self-study and low levels of perceived staff support. Perceived staff support remained an independent variable in multivariate analysis.

Those reporting suicidal thoughts were three times more likely to report low levels of confidence in using the university library (this finding was statistically significant on univariate analysis).

\section{Other Challenges that could lead to DAS}

The answers retrieved from the free-text sections of the questionnaires were analysed and categorised into two themes: life/social challenges and academic challenges. Three main sub-themes were then identified from the answers within each theme, as shown in Table 3.

The qualitative findings echo the quantitative findings in that studying in a different language with a large amount of self-directed learning without frequent support from academics may lead to isolation. This, together with missing home, feeling lonely and having to adjust to life in the UK, are major problems facing our international postgraduate students.

\section{Preferred Source(s) of Support for Students with DAS and Suicidal Thoughts}

We also gathered data on coping strategies used by respondents with DAS $(n=123)$ and suicidal thoughts $(n=34)$ to alleviate their psychological distress. As shown in Figure 2, overall, patterns were similar with the majority having spoken with close friends or families in the UK, or someone in their home countries and tutor or academic advisor. Although those with DAS were more likely to have spoken with a healthcare professional (doctor or nurse $31(25 \%)$ about their psychological distress compared with those who reported suicidal thoughts (doctor or nurse $7(21 \%)$, the use of antidepressant medication was more common amongst those who reported suicidal thoughts: 11(32\%) of respondents with suicidal thoughts reported taking anti-depressant medication (only $7(21 \%)$ of whom had seen a doctor/nurse in the UK) compared with 21 (17\%) of those with DAS.

Table 3

Summary of qualitative findings 
Theme 1: Life/Social challenges

Communication 84 British accent was fast and difficult to understand in academic barrier sessions and at other occasions. Difficulties expressing their academic performance. feelings in either written or spoken English with impact on their

"Because my English is not good and I am nervous to talk with people who speaks in different language with me" (Female MSc student).

"Hard to express what's in my thoughts to words. I am struggling in writing for my assignment" (Female MSc student).

Missing home $\quad 51 \quad \begin{aligned} & \text { Adjusting to or socialising in a culturally diverse environment was a } \\ & \text { difficult task. This made them feel homesick because they felt } \\ & \text { separated from families and friends. }\end{aligned}$

Weather $\quad 91$ Weather was unpredictable in the UK compared to their home change countries. Struggled with attending lectures during the winter when most courses at the university commenced.

"I constantly think about them [family] that I even find it difficult to concentrate on my studies at times" (Female MSc student).

"I live a little far away from school, and it really rains a lot. Sometimes I choose to skip the lessons to stay at home because of the weather" (Female MSc student).

"The unpredictable weather and the winter stress" (Male MSc student).

Theme 2: Academic challenges

Learning style $\quad 35$ Limited access to group learning and workshops, which could have served as a more practical way of learning.

"Majority of one's time during the programme is spent doing independent work. It is sometimes hard to know where to seek help from when you need it" (Female MSc student).

Support from $\quad 36 \quad$ Limited support provided by university staff which affected their university staff $\quad$ decision-making during their course work and that many attributed to very busy staff schedule.

"There are times I need to brain storm or engage in an intellectual discourse, this has not been made extremely available, the process is isolating" (Female MSc student).

"Many tutors have been really helpful, but don't really have the time to work with students one-onone...there should be more time allocated for that" (Female MSc student).

Confident directing selflearning
24 Studying in a new language was a significant barrier to self-directed learning as using the internet to study and to extract useful materials online was problematic. This resulted in having limited confidence and lacking technical skills.
"English is my second language, so sometimes I have some troubles to understand the contents of textbooks and other learning materials" (Female MSc student).

"I don't know the search techniques" (Female MSc student).

$\star \star \star$ IIlustrative quotes are reproduced verbatim; $\mathrm{N}=$ number of responses

\section{Discussion}

We present the findings of a study investigating DAS in international postgraduates studying at a large UK university seeking to generate indicators of risk factors in order to guide intervention development. In this self-selected group of students, we demonstrated a DAS prevalence of $43 \%$ who scored $\geq$ 5 in the SRQ-20 about their situation in 'the recent days or at the current time'. Furthermore, in our study, $12 \%$ of students experienced suicidal thoughts, although only three quarters of these had DAS symptoms. This suggests that the interaction of internal and external factors contributes to the development of DAS. Surprisingly, those with a longer in the UK who may have been expected to have adjusted were at higher risk, as were those studying Arts and Humanities that may be considered less demanding compared to STEM subjects. Living in the UK as an international student posed both academic and sociocultural challenges. Sociocultural issues included financial; coping with the new country setting; poor social support; loneliness; and feeling unwelcome, lead to students seeking support predominantly from friends and family in their home countries. Academically, despite the university providing extensive support services such as library, translation and writing for international students, a significant number of students with DAS or suicidal thoughts encountered major challenges such as having to adopt an independent learning style, use of library and a perception of poor staff support, and language. In spite of the ease of access to counselling and medical services at the researched university, only about $25 \%$ and $22 \%$ respectively sought these services. A number of students on medication for DAS appeared to have received these from their home countries or other sources, rather than seeing a medical doctor in the UK.

\section{Rates of DAS and Suicidal Thoughts}

Although different instruments were used for detection of DAS amongst studies of the UK general population, the DAS rate in our study is significantly higher than reported DAS levels amongst the UK general population (19.7\% DAS prevalence using the GHQ-12 with a cut-off score of $\geq 4$ ) (32). 
However, the DAS prevalence in this study is similar to other studies of global international postgraduates. For example, an on-line survey of 551 international postgraduate students in the US, demonstrated a DAS prevalence of $44 \%$ (19). Another study of postgraduate medical trainees in Bangladesh using the Hamilton Rating Scale for Depression (HAM-D) showed 40\% (33), while the prevalence was still higher among international medical postgraduates in Malaysia (54\%) using the General Health Questionnaire (GHQ-28 cut-off score of $\geq 4.5)(34)$. Although these papers studied different subpopulations, similar DAS prevalence rates across studies can also be attributed to the relation between DAS and the academically challenging environments most international or postgraduate students face $(35,36)$.

In terms of suicidal thoughts, the evidence is conflicting and no data exists for international postgraduate students. Two studies in the USA found lower rates in postgraduates $(7.3 \%(37)$ and $1.6 \%(20))$ though these were not specifically international students. Our rates are consistent with undergraduate studies thus far published: $12 \%$ in a medical residents in the Netherlands (38), $14 \%$ in Norwegian medical students (39), and $11.1 \%$ in American undergraduates using the PHQ-9 (40). Thus, differences may be explained by the demographics of the subpopulations studied. Moreover, international postgraduate students experiencing higher levels of DAS are likely to show higher levels of suicidal thoughts as well and social isolation, a risk factor for suicidality, may have accounted for the higher rates of suicidal thoughts (41).

In our study, a quarter of those with suicidal thoughts had lower SRQ-20 scores than those who did not report suicidal thoughts (24\%). This finding is anti-intuitive, since suicidal ideation often is a symptom of emotional disorders such as DAS (42). However, SRQ-20 was designed to detect DAS and not suicidal ideation (there is only one question about suicidal ideation), and accurate prediction of suicide attempts amongst high-risk and less highrisk patients remains indistinct and relationships such as the above are not fully understood (42).

\section{Predictors of DAS}

In our study, certain factors contributed to DAS which can be said to be specific to being a postgraduate and/or an international student. For example, Arts and Humanities students had the highest risk of DAS. This is consistent with a study of graduate students in California where increased DAS levels amongst arts students was due to factors such as career prospects after graduation (43). However, more relevant to postgraduate international students is that such courses in the UK often involve less directive teaching (leading to the need for more independent study) and less face-to-face time with academic staff compared to science courses $(44,45)$. Quantitative and qualitative data supported students' dislike for the strong emphasis on independent study with significantly lower confidence in managing their own self-directed learning and showing a greater preference towards in-person tutor groups. However, respondents generally felt unsupported in their postgraduate studies. Other factors present in our qualitative data, which contributed to academic related stress included language difficulties, e.g. difficulties understanding a fast-paced British accent and low confidence in articulating the complexity of their academic points in English, rendering them unable to engage in many academic activities. Fear that these challenges would impact their academic success was common. Research suggests that social support and English literacy constitute significant protective factors against depression in students $(46,47)$. Social support serves as a coping mechanism for stress and can override negative perceptions in periods of stress (46). Accordingly, fluency in English can facilitate social interactions, friendships, cultural integration and ease homesickness.

Furthermore, such challenges (learning style, language and need for greater academic support) can lead to students questioning their own academic potential (reduced confidence) and consequently further stress and depression (48). Similar challenges were reported in an ethnographic study of international postgraduate students in the UK in 2008 (22) which found that students who were often high-achieving in their home countries where they had good communication skills and were familiar with the higher education culture struggled with new unfamiliar challenges faced in their host countries. While it may be assumed that such difficulties may be resolved with time, our study demonstrated that students who stayed in the UK for $>3$ years had a significant 3-fold higher risk of DAS when compared to others who were in the UK for $<3$ years. One possible explanation could be that these are final year PhD students with greater stress while completing their thesis (49). Alternative explanations supported by our data (including free text) may include: long-term distance from family (and social and practical support networks); problems with personal relationships; financial issues (possibly due to long period of not earning an adequate salary and having to support family at home); racism (22); and difficulty adapting to the host culture $(50,51)$. Other studies have cited the concept of "cultural stress" which may impact the psychological wellbeing of international students, especially when the host country shares different cultural values $(51,52)$. Cultural distance may exacerbate feelings of loneliness and isolation which are common features of depressive episodes that may come with living in an unfamiliar environment (51).

Moreover, we had a large proportion of students from South Asia and Africa for whom the cold and rain in the UK may be a challenge. Students reported stress due to the unpredictable British weather (both rainy weather and in winter months), which interrupted their journeys to university and forced some to skip academic sessions. Some may even experience a form of seasonal affective disorder (53).

The published literature has cited additional factors with increased DAS levels amongst postgraduate students, such as being married whilst at university (54) and being on a "taught" lecture-based course (in the UK this equates to masters courses with heavy work load) (55). The direction of association in our results reflected these evidence, but they were not statistically significant and could be due to our small sample size. Although more female students had DAS and suicidal thoughts (in line with previous studies $(18,56-59)$ ) this was also not statistically significant.

Therefore, in our study, the challenges specific to the international student experience (e.g. distance from and missing home, social and practical support networks, difficulty communicating in a second language, financial and academic pressures, navigating in a different academic and sociocultural environment, predisposing mental illness, and weather) may explain the higher DAS levels amongst our international postgraduate students. 


\section{DAS and Coping Strategies}

The main coping strategy used for those experiencing DAS and suicidal thoughts was speaking to friends and family; a similar proportion talked to people at home as often as in the UK. This has also been demonstrated in other studies $(3,60)$. Recent literature supports our findings that there is a shift in the support network of international students the longer they live in their host countries, with students relying more on home within their host countries for emotional support as their length of stay in the host country lengthens (61). Other avenues for support include from a religious counsellor, academic advisor or a healthcare professional, all of these were also reported by our population (22). Interventions provided by some universities (including the one we surveyed) include psychological support, such as offering cognitive and psychological behavioural therapies $(19,62)$ which, though important for some of our respondents, seem not to have reached the majority who may have needed it. These findings indicate a need for creative methods to better promote these services with the vulnerable international postgraduate students.

The question needing further research is: 1) why our respondents have not accessed academic and psychosocial support that was offered by university; and 2) whether this was because support was inadequate, inappropriate, and inaccessible (for a range of possible reasons including timing and scale of service) or that the international postgraduate students were simply unaware of them? Qualitative data on the preferred coping strategies among respondents was not obtained in our study; however, other studies report that students often did not pursue formal counselling or medical services out of fear of stigmatisation, lack of confidence in their foreign language skills, or potential prejudice against their religious and cultural beliefs $(3,60)$. Medication use was twice as common in those with suicidal thoughts compared to those with DAS, possibly because they were more likely to have been previously diagnosed with mental health problems, which may require pharmacological treatment (63). It seems that some may have been on medication from their home country since in the UK only doctors prescribe such medications while they said they had not seen a doctor in the UK. This points to the need for such students to be better connected with university health services in order to ensure appropriate and prompt prescribing for their mental health conditions. It is important to review the information and availability of specialist health services at the host universities and to ensure that it is appropriately communicated to the students.

\section{A model for Factors influencing DAS in International Postgraduates}

Although further research is needed, we offer a model for predictors of DAS in postgraduate international students in order to inform practice and policy. We used previous research on international postgraduate students, psychosocial and diathesis schemas to understand the role of exogenous and endogenous factors in the development of DAS (64). Based on our own and reviewed evidence, we might reason that international students comprise a high-vulnerability/susceptible group (65) due to different characteristics (compared to under-graduate and non-international students), such as, a higher social and work status pre-enrolment on the postgraduate course, significantly higher familiarity with academic and other systems in their home country, a greater likelihood of being mature students with family to support and who cannot support them in the host university. Those who bring family to the host university, have the added difficulty of supporting them in an unfamiliar setting in addition to studying. These constitute a combination of student, home and host country factors of exogenous and endogenous origin. These are presented in Fig. 3.

In their home countries, a greater emphasis on self-learning and independent study, management of daily chores, and English proficiency (written, listening and speaking skills) may help protect students during their study away from home. In the host countries, measures and support that address academic and sociocultural issues in Fig. 3 may provide a supportive and protective environment against DAS.

Figure 3

\section{Strengths and Limitations of the study}

A self-selecting sampling methodology could lead to response bias that could either reduce or increase the number of DAS affected students responding, as some students affected with DAS may not have wished to remind themselves of their symptoms. Conversely, a higher proportion of DAS students may have participated since they were motivated by their problems and glad to share their views, and lower proportion of those not affected may have participated as it was not a priority for them. Considering that the study was conducted during spring and summer periods, some postgraduate students may not have been available to participate due to exam periods or their studies concluding, though this seems not to introduce an inherent bias. Lastly, although the survey was anonymous, social acceptability bias may have reduced reporting symptoms, since some may have felt the nature of the topic is private.

The strengths of this study were the adoption of the cross-culturally validated SRQ-20 item questionnaire to identify DAS, exploration of possible predictors and challenges, and coping mechanisms that are associated with DAS using mixed methods, among international postgraduates in a large UK university.

\section{Conclusion}

The mental health status of university students is of great concern to public and policy makers alike $(6,7)$. International postgraduates are an important group of students in high-income country universities and often go on to achieve positions of influence in their home countries, particularly if they originate from LMICs. We found that international postgraduates were vulnerable to higher rates of DAS and suicidal thoughts than the general UK population and the UK born student population, which will potentially affect the former's academic performance and future outcomes. This is particularly concerning given the existing pressures on student mental health services $(6,7)$. This was associated with several factors including length 
of stay in the UK and studying certain subjects. Being international students, they experienced additional academic and environmental challenges during their transition to a university in a foreign country which may have contributed to depression and anxiety symptoms. Additionally, postgraduate international students often represent a high-achieving group of future professionals who have not been accustomed to isolation nor poor outcomes for study or work. Acculturation, feelings of rejection and academic difficulties, pre-existing mental health problems, and subsequent symptoms may account for poorer mental health outcomes. Interventions in the home countries and the host universities' ability to identify effective strategies and implement targeted high quality support measures will help to reduce psychological stress amongst this population and improve their quality of life and academic outcomes. However, existing services were not taken up optimally pointing to the need for more complex mental health strategies that should be culturally informed and tailored around each student's needs given the diverse background of international and furthermore postgraduate students, as well as effectively advertised and universally accessible. In order to develop targeted resources in UK universities, we need further research to understand and address the issues that affect these students. This study has made a contribution in this area. Further studies across multiple universities need to examine what mechanisms, policies and procedures are in place to respond to international students experiencing a mental health crisis and aim to monitor minimum standard policies and practice in order to intervene early by acknowledging the vulnerabilities of this large group of students.

We also suggest a re-evaluation of the way the SRQ-20 questionnaire is used to screen for mental health problems, as some participants who reported suicidal thoughts had lower SRQ-20 scores than those without suicidal thoughts and some did not score for DAS at all, despite suicidal ideation being a sign of more severe depressive disorders.

\section{Abbreviations}

Cl: Confidence Interval

DAS: Depression, Anxiety and Stress

$\mathrm{N}$ : Number

OECD: Organisation for Economic Co-operation and Development

OR: Odd Ratio

PHQ: Patient Health Questionnaire

SRQ: Self-Reporting Questionnaire

ST: Suicidal thoughts

STEM: Science, Technology, Engineering, and Mathematics

UK: United Kingdom

USA: United States of America

$\%$ : Percentage

\section{Declarations}

\section{Ethics approval and consent to participate}

The Ethics Review Committee of the University approved the research on the $6^{\text {th }}$ of July, 2015 (Ethical Review ERN_15-0369). We confirm that all methods in this study were carried out in accordance with relevant guidelines and regulations. Informed consent was obtained from the respondents. For students in need of support, information was provided on how to seek help in case of psychological distress.

\section{Consent for publication}

Not applicable

\section{Availability of data and materials}

The data set used and analysed in this study are available from the corresponding author on reasonable request.

\section{Competing interests}


The authors declare that they have no competing interests.

\section{Funding}

This research was the final Masters project for OCE funded by Dr Mrs Roseleen K. Mba-Kalu. No other specific funding was received for this study from funding agencies in the public, commercial, or not-for-profit sectors.

\section{Authors' contributions}

OCE and supervisors SMH and AL conceptualised and designed the study and developed the questionnaire. OCE conducted the literature review, conducted the data collection and field work, data analysis. Authors $\mathrm{OCE}, \mathrm{SMH}, \mathrm{ML}, \mathrm{AL}$, and $\mathrm{HK}$ all contributed towards data interpretation, and various drafts of the manuscript. CU contributed to the analysis of data and interpretation of findings.

\section{Acknowledgement}

The authors would like to appreciate Dr Jesse Kigozi, Dr Krish Nirantharakumar and Dr Malcolm J. Price for their support during the conduct of this research.

\section{References}

1. OECD. Education at a Glance 2019: OECD Indicators [Internet]. Paris: OECD Publishing; 2019; 234-242 p. [Cited 2020 Apr 25]. Available from: http://doi.org/10.1787/f8d7880d-en

2. Royal College of Psychiatrists. Mental health of students in higher education Royal College of Psychiatrists. Coll Rep CR166 R Coll Psychiatr [Internet]. 2011;32-63. [Cited 2015 Jul 5]. Available from: www.rcpsych.ac.uk/files/pdfversion/cr166.pdf

3. Mori SC. Addressing the Mental Health Concerns of International Students. J Couns Dev [Internet]. 2000 Apr 23;78(2):137-44. [Cited 2015 Dec 12]. Available from: http://doi.wiley.com/10.1002/j.1556-6676.2000.tb02571.x

4. Mellors-Bourne R, Humfrey C, Kemp N, Woodfield S. The Wider Benefits of International Higher Education in the UK. BIS Res Pap Number 128 [Internet]. 2013;September(128):1-108. [Cited 2018 Jun 18]. Available from: https://www.gov.uk/government/uploads/system/uploads/attachment_data/file/240407/bis-13-1172-the-wider-benefits-of-international-highereducation-in-the-uk.pdf

5. Office for Students. Equality and diversity [Internet]. Office for Students; 2018 Sep. [Cited 2019 Oct 12]. Available from: https://www.officeforstudents.org.uk/data-and-analysis/equality-and-diversity/

6. The Guardian. Levels of distress and illness among students in UK “alarmingly high" | Education | The Guardian [Internet]. [Cited 2019 Oct 12] Available from: https://www.theguardian.com/education/2019/mar/05/levels-of-distress-and-illness-among-students-in-uk-alarmingly-high

7. The Guardian. UK students waiting up to three months for mental health care | Society | The Guardian [Internet]. [Cited 2019 Oct 12]. Available from: https://www.theguardian.com/society/2019/sep/16/uk-students-waiting-up-to-three-months-for-mental-health-care

8. Kiekens G, Hasking P, Claes L, Mortier P, Auerbach RP, Boyes M, et al. The DSM-5 nonsuicidal self-injury disorder among incoming college students: Prevalence and associations with 12-month mental disorders and suicidal thoughts and behaviors. Depress Anxiety [Internet]. 2018 Jul;35(7):62937. [Cited 2019 Feb 11]. Available from: http://doi.wiley.com/10.1002/da.22754

9. Arnett JJ, Žukauskiene R, Sugimura K. The new life stage of emerging adulthood at ages 18-29 years: Implications for mental health. The Lancet Psychiatry [Internet]. 2014 Dec;1(7):569-76. [Cited 2019 Feb 11]. Available from: http://www.ncbi.nlm.nih.gov/pubmed/26361316

10. Kessler RC, Berglund P, Demler O, Jin R, Merikangas KR, Walters EE. Lifetime Prevalence and Age-of-Onset Distributions of DSM-IV Disorders in the National Comorbidity Survey Replication. Arch Gen Psychiatry [Internet]. 2005;62(6):593. [Cited 2019 July 25]. Available from:

http://archpsyc.jamanetwork.com/article.aspx?doi=10.1001/archpsyc.62.6.593

11. Blanco C, Okuda M, Wright C, Hasin DS, Grant BF, Liu S-M, et al. Mental health of college students and their non-college-attending peers: results from the National Epidemiologic Study on Alcohol and Related Conditions. Arch Gen Psychiatry [Internet]. 2008;65(12):1429-37. [Cited 2019 July 15] Available from: http://www.ncbi.nlm.nih.gov/pubmed/19047530\%0Ahttp://www.pubmedcentral.nih.gov/articlerender.fcgi?artid=PMC2734947

12. World Health Organization. Mental disorders [Internet]. 2014. [Cited 2015 Jul 16]. Available from: http://www.who.int/mediacentre/factsheets/fs396/en/

13. Mills, Harry; Reiss, Natalie; Dombeck M. The Nature of Stress: Mental and Emotional Impact of Stress [Internet]. 2008. [Cited 2017 Jun 7]. Available from: https://www.mentalhelp.net/articles/mental-and-emotional-impact-of-stress/

14. Silverman MM, Meyer PM, Sloane F, Raffel M, Pratt DM. The Big Ten Student Suicide Study: A 10-Year Study of Suicides on Midwestern University Campuses. Suicide Life-Threatening Behav. 1997;27(3):285-303.

15. Ibrahim AK, Kelly SJ, Adams CE, Glazebrook C. A systematic review of studies of depression prevalence in university students. J Psychiatr Res [Internet]. 2013 Mar;47(3):391-400. [Cited 2015 Oct 12]. Available from: http://www.sciencedirect.com/science/article/pii/S0022395612003573

Page $16 / 21$ 
16. Bewick B, Gill J, Mulhearn B. Using electronic surveying to assess psychological distress within the UK student population: a multi-site pilot investigation. E-Journal Appl [Internet]. 2008;4(2):1-5. [Cited 2015 Aug 10]. Available from: http://eresearch.qmu.ac.uk/845/

17. Macaskill A. The mental health of university students in the United Kingdom. Br J Guid Counc [Internet]. 2013;41(4):426-41. [Cited 2018 Feb 7]. Available from: http://shura.shu.ac.uk/6449/

18. Mcmanus S, Bebbington P, Jenkins R, Brugha T. Mental health and wellbeing in England Adult Psychiatric Morbidity Survey 2014 Execuytive Summary. Leeds NHS Digit [Internet]. 2016;1-405. [Cited 2016 May 11]. Available from: http://content.digital.nhs.uk/catalogue/PUB21748/apms2014-full-rpt.pdf

19. Hyun J, Quinn B, Madon T, Lustig S. Mental health need, awareness, and use of counseling services among international graduate students. J Am Coll Health [Internet]. 2007;56(2):109-18. [Cited 2015 May 10]. Available from: http://www.ncbi.nlm.nih.gov/pubmed/17967756

20. Eisenberg D, Gollust SE, Golberstein E, Hefner JL. Prevalence and correlates of depression, anxiety, and suicidality among university students. Am J Orthopsychiatry. 2007;77(4):534-42.

21. Forbes-Mewett H. Mental Health and International Students: Issues, challenges and effective practice [Internet]. Melbourne: International Education Association of Australia (IEAA); 2019. [Cited 2020 Apr 28]. Available from:

https://www.researchgate.net/publication/334721342_Mental_Health_and_International_Students_Issues_challenges_effective_practice

22. Brown L, Holloway I. The adjustment journey of international postgraduate students at an English university: An ethnographic study. J Res Int Educ. 2008;7(2):232-49.

23. Select Statistical Consultants Services. Sample Size Calculator: Population Proportion [Internet]. 2015. [Cited 2015 Nov 7]. Available from: http://www.select-statistics.co.uk/sample-size-calculator-proportion

24. Free Online Surveys \& Questionnaires From SmartSurvey [Internet]. 2015. [Cited 2015 Nov 8]. Available from: https://www.smartsurvey.co.uk/

25. World Health Organization. A user's guide to the Self Reporting Questionnaire (SRQ) [Internet]. Geneva: World Health Organization. 1994. p. 1-84. [Cited 2015 Mar 8]. Available from: http://whqlibdoc.who.int/hq/1994/WHO_MNH_PSF_94.8.pdf

26. Yeoh JSW, Terry DR. International Research Students' Experiences in Academic Success. Univers J Educ Res. 2013;1(3):275-80.

27. Ludermir AB, Lewis G. Links between social class and common mental disorders in Northeast Brazil. Soc Psychiatry Psychiatr Epidemiol [Internet]. 2001 May 16;36(3):101-7. [Cited 2016 Oct 26]. Available from: http://link.springer.com/10.1007/s001270050297

28. El-Rufaie OEF, Absood GH. Validity study of the Self-Reporting Questionnaire (SRQ-20) in primary health care in the United Arab Emirates. Int J Methods Psychiatr Res. 1994;

29. Husain N, Chaudhry N, Rhouma A, Sumra A, Tomenson B, Waheed W. Validation of the self-reporting questionnaire (SRQ 20) in British Pakistani and White European population in the United Kingdom. J Affect Disord. 2016;189:392-6.

30. Braun V, Clarke V. Using thematic analysis in psychology. 2006:37-41. [Cited 2015 Aug 5]. Available from: http://eprints.uwe.ac.uk/11735/1/thematic_analysis_revised_-_final.doc

31. O'Cathain A, Thomas KJ. "Any other comments?" Open questions on questionnaires - a bane or a bonus to research? BMC Med Res Methodol [Internet]. 2004 Nov 8;4(1):25. [Cited 2015 Oct 22]. Available from: http://www.biomedcentral.com/1471-2288/4/25

32. Randall C, Corp A, Self A. Measuring National Well-Being: LIfe in the UK. Off Natl Stat;(February):1-52.

33. Zaman S, Rahim MA, Afroz F, Afroz SR, Haque HF, Ahmed JU, et al. Prevalence of Depression Among Post-Graduate Medical Trainees: A MultiCentre Survey. Birdem Med J [Internet]. 2014 Apr 9;4(1). [Cited 2016 Oct 28]. Available from:

http://www.banglajol.info/index.php/BIRDEM/article/view/18548

34. Hussein OM, bt Zainal NZ, Abdel-Latif ME. Prevalance of stress among international post-graduate doctors at the University Malaya Medical Centre (UMMC), Kuala Lumpur. J Clin Diagnostic Res. 2012;6(June):859-62.

35. Shamsuddin K, Fadzil F, Ismail WSW, Shah SA, Omar K, Muhammad NA, et al. Correlates of depression, anxiety and stress among Malaysian university students. Asian J Psychiatr [Internet]. 2013;6(4):318-23. [Cited 2015 Aug 15]. Available from:

http://dx.doi.org/10.1016/j.ajp.2013.01.014

36. Dyrbye LN, Thomas MR, Shanafelt TD. Systematic review of depression, anxiety, and other indicators of psychological distress among U.S. and Canadian medical students. Acad Med [Internet]. 2006 Mar;81(4):354-73. [Cited 2016 Sep 12] Available from:

http://eutils.ncbi.nlm.nih.gov/entrez/eutils/elink.fcgi?dbfrom=pubmed\&id=16565188\&retmode=ref\&cmd=prlinks

37. Garcia-Williams AG, Moffitt L, Kaslow NJ. Mental Health and Suicidal Behavior Among Graduate Students. Acad Psychiatry [Internet]. 2014 Oct 8;38(5):554-60. [Cited 2016 Sep 12]. Available from: http://link.springer.com/10.1007/s40596-014-0041-y

38. Van der Heijden F, Dillingh G, Bakker A, Prins J. Suicidal Thoughts Among Medical Residents with Burnout. Arch Suicide Res [Internet]. 2008;12(4):344-6. [Cited 2016 Sep 12]. Available from: http://www.tandfonline.com/doi/abs/10.1080/13811110802325349

39. Tyssen R, Vaglum P, Grønvold NT, Ekeberg $\emptyset$. Suicidal ideation among medical students and young physicians: a nationwide and prospective study of prevalence and predictors. J Affect Disord [Internet]. 2001 Apr;64(1):69-79. [Cited 2018 April 24]. Available from:

http://linkinghub.elsevier.com/retrieve/pii/S0165032700002056

40. Garlow SJ, Rosenberg J, Moore JD, Haas AP, Koestner B, Hendin H, et al. Depression, desperation, and suicidal ideation in college students: Results from the American Foundation for Suicide Prevention College Screening Project at Emory University. Depress Anxiety. 2008;25(6):482-8.

Page 17/21 
41. Zhou H, Wang Z, Xu Y. Risk Factors of Suicide Ideation in Chinese Graduate Students: CHAID Tree Analysis. Can Soc Sci [Internet]. 2017 Sep 13(9):29-33. 26 [Cited 2020 Apr 26], Available from: http://www.cscanada.net/index.php/css/article/view/9857

42. Nemeroff CB, Compton MT, Berger J. The Depressed Suicidal Patient: Assessment and Treatment. Ann N Y Acad Sci [Internet]. 2001 Jan 25;932(1):1-23. [Cited 2019 Feb 11]. Available from: http://doi.wiley.com/10.1111/j.1749-6632.2001.tb05795.x

43. Graduate Assembly. Graduate Student Happiness \& Well-Being Report [Internet]. 2014; 1-62 p. [Cited 2017 Oct 5]. Available from: http://ga.berkeley.edu/wp-content/uploads/2015/04/wellbeingreport_2014.pdf

44. Danov M. Teaching international commercial arbitration at postgraduate level - techniques for enhancing students' learning. Law Teach [Internet]. 2011 Feb 8;45(1):101-13. [Cited 2019 Feb 5]. Available from: http://www.tandfonline.com/doi/abs/10.1080/03069400.2011.546968

45. Brown L. The incidence of study-related stress in international students in the initial stage of the international sojourn. J Stud Int Educ [Internet]. 2008;12(1):5-28. [Cited 2019 Feb 5]. Available from: https://core.ac.uk/download/pdf/76203.pdf

46. Shadowen NL, Williamson AA, Guerra NG, Ammigan R, Drexler ML. Prevalence and correlates of depressive symptoms among international students: Implications for university support offices. J Int Students. 2019;9(1):130-49.

47. Sümer S, Poyrazli S, Grahame K. Predictors of Depression and Anxiety Among International Students. J Couns Dev [Internet]. 2008 Oct 23;86(4):429-37. [Cited 2015 Dec 7]. Available from: http://doi.wiley.com/10.1002/j.1556-6678.2008.tb00531.x

48. Pellegrino Aveni VA. Study abroad and second language use: Constructing the self. Cambridge: Cambridge University Press; 2005. 1-188 p.

49. Levecque K, Anseel F, De Beuckelaer A, Van der Heyden J, Gisle L. Work organization and mental health problems in PhD students. Res Policy [Internet]. 2017 46(4):868-79. [Cited 2017 Oct 3]. Available from: https://ac.els-cdn.com/S0048733317300422/1-s2.0-S0048733317300422main.pdf?_tid=d7a0a8f8-a88b-11e7-9995-00000aab0f01\&acdnat=1507070603_1096c556ccf07ccccf37b8db8358316d

50. Ward C, Okura Y, Kennedy A, Kojima T. The U-curve on trial: A longitudinal study of psychological and sociocultural adjustment during crosscultural transition. Int J Intercult Relations. 1998;22(3):277-91.

51. Thomson G, Rosenthal D, Russell J. Cultural stress among international students at an Australian university. Aust Int Educ Conf 2006. 2006;1-8.

52. Desa A, Yusooff F, Kadir NBA. Acculturative Stress Among International Postgraduate Students at UKM. Procedia - Soc Behav Sci [Internet]. 2012;59:364-9. [Cited 2019 Oct 10]. Available from: http://www.sciencedirect.com/science/article/pii/S1877042812037354

53. Sandman N, Merikanto I, Määttänen H, Valli K, Kronholm E, Laatikainen T, et al. Winter is coming: nightmares and sleep problems during seasonal affective disorder. J Sleep Res [Internet]. 2016 Oct 1;25(5):612-9. [Cited 2018 Nov 14]. Available from: http://doi.wiley.com/10.1111/jsr.12416

54. Bayram N, Bilgel N. The prevalence and socio-demographic correlations of depression, anxiety and stress among a group of university students. Soc Psychiatry Psychiatr Epidemiol [Internet]. 2008 Aug;43(8):667-72. [Cited 2015 Feb 19]. Available from: http://link.springer.com/article/10.1007/s00127-008-0345-x/fulltext.html

55. Poyrazli S, Kavanaugh PR. Marital status, ethnicity, academic achievement, and adjustment strains: The case of graduate international students. Coll Stud J [Internet]. 2006;40(4):767-80. [Cited 2017 Oct 10]. Available from:

https://s3.amazonaws.com/academia.edu.documents/37635758/2006_College_Student_J_Article.pdf?

AWSAccessKeyld=AKIAIWOWYYGZ2Y53UL3A\&Expires=1507646560\&Signature=o0A2tQNVFMobswn8\%2FCxbSQERmnw\%3D\&response-contentdisposition=inline\%3B filename\%3DMarital_Statu

56. Nolen-Hoeksema S, Girgus JS. The emergence of gender differences in depression during adolescence. Psychol Bull. 1994;115(3):424-43.

57. Hankin BL, Abramson LY, Moffitt TE, Silva PA, McGee R, Angell KE. Development of depression from preadolescence to young adulthood: emerging gender differences in a 10-year longitudinal study. J Abnorm Psychol [Internet]. 1998 Feb;107(1):128-40. [Cited 2015 Sep 21]. Available from: http://www.ncbi.nlm.nih.gov/pubmed/9505045

58. World Health Organization. Gender and women's mental health [Internet]. World Health Organization; 2014. [Cited 2015 Aug 17]. Available from: http://www.who.int/mental_health/prevention/genderwomen/en/

59. Wilhelm K, Roy K, Mitchell P, Brownhill S, Parker G. Gender differences in depression risk and coping factors in a clinical sample. Acta Psychiatr Scand [Internet]. 2002 Jul 1;106(1):45-53. [Cited 2017 Oct 2]. Available from: http://doi.wiley.com/10.1034/j.1600-0447.2002.02094.x

60. Hyams-Ssekasi D, Mushibwe CP, Caldwell EF. International Education in the United Kingdom: The Challenges of the Golden Opportunity for BlackAfrican Students. SAGE Open [Internet]. 2014;4(4):2158244014562386-. [Cited 2018 May 15.] Available from:

http://sgo.sagepub.com/content/4/4/2158244014562386

61. Bhochhibhoya A, Dong Y, Branscum P. Sources of social support among international college students in the United States. J Int Students [Internet]. 2017;7(3):671-86. [Cited 2019 Jun 10]. Available from: https://files.eric.ed.gov/fulltext/EJ1140435.pdf

62. Regehr C, Glancy D, Pitts A. Interventions to reduce stress in university students: a review and meta-analysis. J Affect Disord [Internet]. 2013 May 15;148(1):1-11. [Cited 2015 Oct 5]. Available from: http://www.sciencedirect.com/science/article/pii/S0165032712007793

63. Eikelenboom M, Beekman ATF, Penninx BWJH, Smit JH. A 6-year longitudinal study of predictors for suicide attempts in major depressive disorder. Psychol Med [Internet]. 2018 Jun 13;1-11. [Cited 2019 Nov 10]. Available from:

https://www.cambridge.org/core/product/identifier/S0033291718001423/type/journal_article

64. Schotte CKW, Van Den Bossche B, De Doncker D, Claes S, Cosyns P. A biopsychosocial model as a guide for psychoeducation and treatment of depression. Depress Anxiety [Internet]. 2006 Jan 1;23(5):312-24. [Cited 2020 Apr 27]. Available from: http://doi.wiley.com/10.1002/da.20177

Page 18/21 
65. Suls J, Rothman A. Evolution of the Biopsychosocial Model: Prospects and Challenges for Health Psychology. Heal Psychol [Internet]. 2004;23(2):119-25. [Cited 2020 Apr 27]. Available from: https://www.ncbi.nlm.nih.gov/pubmed/15008654

\section{Figures}

\section{Suicidal thoughts with corresponding SRQ scores}

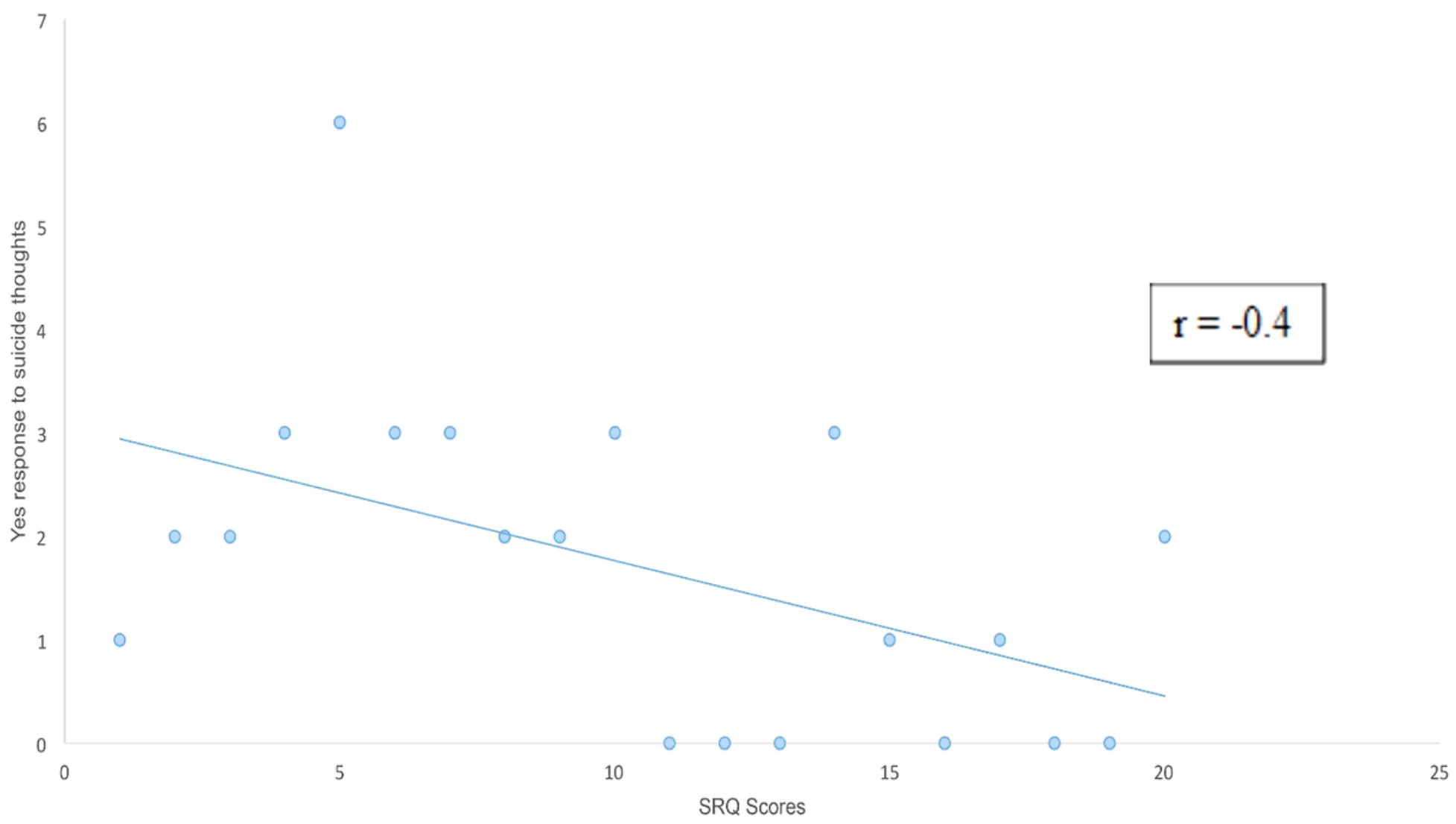

\section{Figure 1}

Scatter plot of respondents with Suicidal Thoughts 


\section{Respondents with DAS and Suicidal Thoughts}

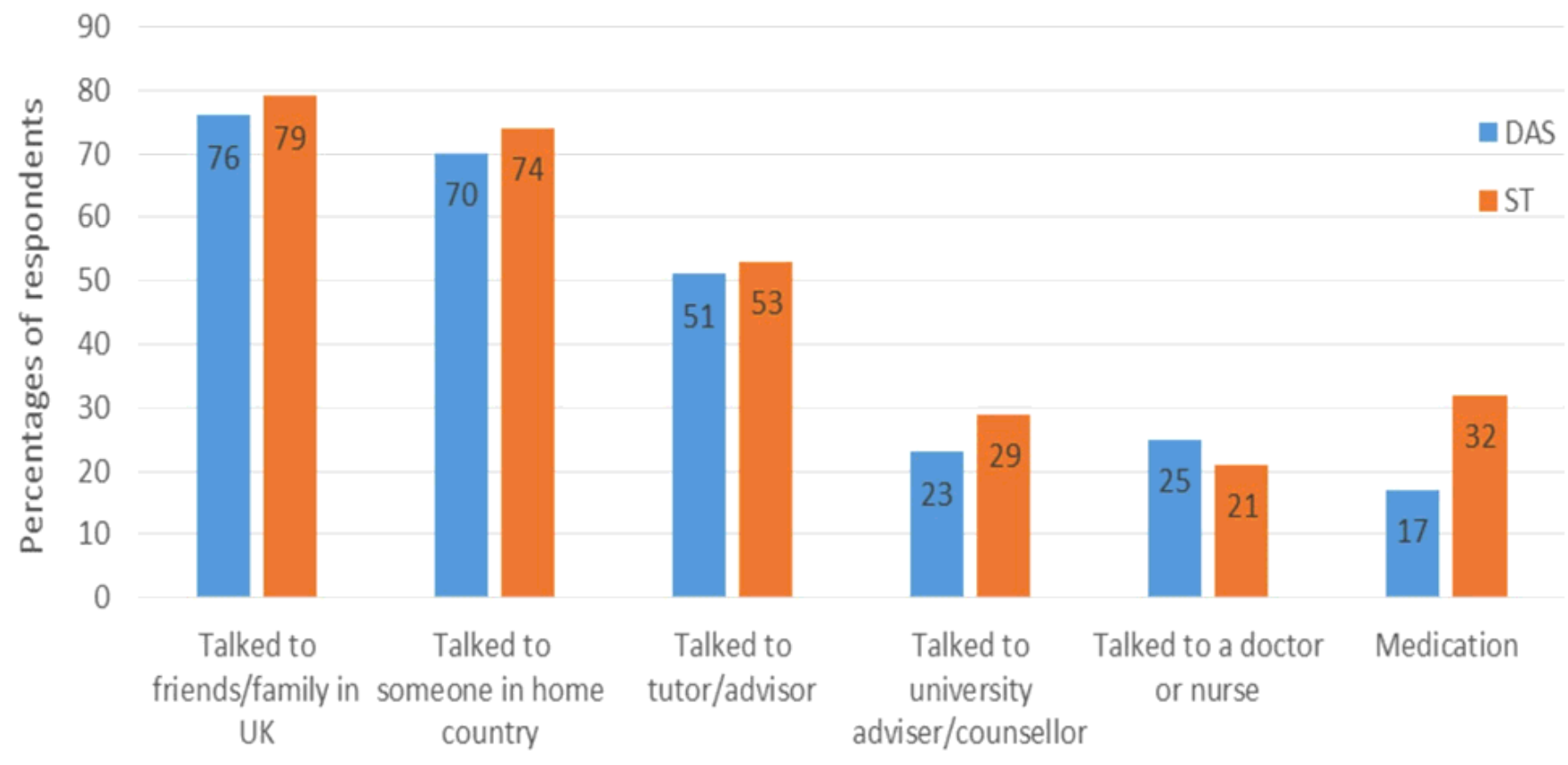

Coping strategies used

Figure 2

Coping strategies used by respondents with DAS $(n=123)$ and Suicidal Thoughts $(n=34)$ in percentages.

\section{Home Country}

International Post-graduate Student \& risk of DAS

\section{Host country}

Exogenous Social/Cultural factors

- Social status due to high achievements

- Help with home \& self-care

- Family \& social support

- Cultural integration \& familiarity

- Less financial stress (often due to status and high achievement)

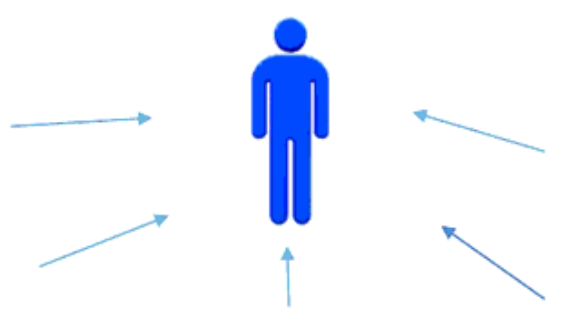

Endogenous/personal factors

- Self-confidence in academic \& other abilities

- Married

- Personality traits

- Female Sex

Pre-existing mental health issues

- Family or life crisis

- Long lengths of stay unsupported

Footnote to Figure 3: We adopted a biopsychosocial approach (64) to categorise the multifactorial predictors of DAS from the literature and our data into student factors (endogenous and circumstantial) and external or exogenous factors (sociocultural, environmental and academic) related to home and host country settings. We suggest that the interaction of these elements can explain the multifactorial outcomes of DAS amongst postgraduate international students and generate negative mental health outcomes during the process of transition and acculturation at the host university. 


\section{Figure 3}

Diagrammatic representation of influences on international postgraduate students contributing to DAS.

\section{Supplementary Files}

This is a list of supplementary files associated with this preprint. Click to download.

- APPENDIXFigureAonFlowChartforBMCManuscriptonDAS.docx

- APPENDIXTableAonFrequencyDistributionforBMCManuscriptonDAS.docx

- APPENDIXTableBonNumberoffreetextresponsesforBMCManuscriptonDAS.docx 